\section{Renal Medullary Necrosis}

Friedreich first described renal medullary necrosis in 1877 in a man with an enlarged prostate and hydronephrosis. ${ }^{1}$ The lesion is a circumscribed, wedge-shaped necrosis of the medullary pyramids especially affecting the distal parts of the papillae. It is usually greyish-yellow in colour, and microscopically it consists of acellular necrotic material separated from the remainder of the parenchyma by a zone of acute inflammation. While in most cases there is a superimposed acute pyelonephritis, the condition may occur in the absence of infection, and the alternative name necrotizing papillitis is to be deprecated. The necrotic papillae may slough off into the urine, leaving a ragged surface at the point of separation. Most patients die of rapidly progressive renal failure, but some have survived. ${ }^{2}$

The condition is described mainly in adults, and the two usual predisposing causes are diabetes mellitus and obstruction of the urinary tract, both being frequently complicated by acute pyelonephritis. ${ }^{3}$ More recently medullary necrosis has been described in association with interstitial fibrosis, ${ }^{4}$ a condition in which a contracted kidney is associated with generalized interstitial scarring, especially at the junction of the necrotic and the normal tissue. The microscopical appearance resembles chronic pyelonephritis, but these cases usually do not show infection; there is often a history of abuse of analgesics. 5 6 Phenacetin is especially incriminated, ${ }^{7}$ but aspirin and other analgesics probably also play a part. ${ }^{8}$

Renal medullary necrosis may occasionally occur in children. ${ }^{9-11}$ D. J. Davies and his colleagues have recently described 18 cases in infants. ${ }^{12}$ Of these only two occurred in children of over six months, and five were found during the first week of life. Thirteen children died during the first week after the onset of the illness, and their kidneys showed haemorrhagic infarction of the medulla, with no clear line of demarcation. The five who died two weeks or more after the onset showed a lesion more closely resembling the adult one; it was better demarcated, and the necrotic areas were acellular. The aetiological factors were asphyxia, dehydration, renal-vein thrombosis, septicaemia, haemorrhage, urinary-tract obstruction, and cyanotic congenital heart disease. The basic cause of the medullary necrosis appeared to be renal ischaemia due to severe, prolonged hypotension, complicated in some cases by thrombosis of the renal veins.

The cause of adult medullary necrosis appears to be more complex. Once again ischaemia is probably an important factor. It could be engendered by a raised intrapelvic pressure in cases of urinary-tract obstruction, by sclerosis of the intrarenal arteries and arterioles in diabetes mellitus, by compression of the medullary vessels from oedema in acute pyelonephritis, and by vasospasm following the hypotension

\footnotetext{
Friedreich, N., Virchows Archiv für pathologische Anatomie und Pathologie, 1877, 69, 308.

Schourup, K., Acta Pathologica et Microbiologica Scandinavica, 1958, 44, 168 .

3 Lauler, D. P., Schreiner, G. E., and David, A., American fournal of Medicine, 1960, 29, 132.

- Schourup, K., Acta Pathologica et Microbiologica Scandinavica, 1957, 41, 462 .

5 Lindvall, N., Acta Radiologica, 1960, suppl. No. 192

Reynolds, T. B., and Edmondson, H. A., Fournal of the American Medical Association, 1963, 184, 435.

British Medical fournal, 1965, 1, 673.

Saker, B. M., and Kincaid-Smith, P., British Medical fournal, 1969, 1, 161 .

- Stirling, G. A., Fournal of Clinical Pathology, 1958, 11, 296.

10 Swartz, D., and Hoogstraten, J., British fournal of Urology, 1959, 31, 419.

11 Bernstein, J., and Meyer, R., fournal of Pediatrics, 1961, 59, 657.

12 Davies, D. J., Kennedy, A., and Roberts, C., Fournal of Pathology, 1969, 99,125 .

${ }^{13}$ Green, C. R., Ham, K. N., and Tange, J. D., British Medical fournal, $1969,1,162$.
}

due to dehydration in diabetic ketosis. Infection itself could cause some of the lesions. The aetiology of medullary necrosis in analgesic nephropathy is obscure. It is possible that a metabolite of phenacetin has a directly toxic effect. Rats given a compound structurally related to phenacetin developed a necrotic lesion of the terminal parts of the proximal convoluted tubules, and this was followed by an extensive chronic inflammatory reaction in the interstitial tissue beyond the zone of injury. ${ }^{13}$ Whether this is a true counterpart of the human lesion remains to be seen. In any case the relation between interstitial fibrosis and medullary necrosis is not apparent.

\section{Nonspecific Lung Abscess}

About one-half of all lung abscesses apart from those due to pulmonary tuberculosis can be neatly classified according to their antecedents. They are complications of a recognizable cause-for example, a specific pneumonia, bronchial occlusion, pulmonary infarction, or trauma. Though the rest are a mixed bag they have much in common. They often follow the inhalation of foreign material, their anatomical distribution is characteristic, and they usually resolve with thorough antibiotic therapy.

The idea of an aspiration lung abscess derives principally from the studies of Lord Brock, ${ }^{1}$ who showed radiologically the most likely resting-places of small quantities of iodized oil when they were inhaled in the recumbent position. These places were the posterior segment of the upper lobe and the apex of the lower lobe when the patient was supine and the axillary part of the lung when he was lying on his sideprecisely the sites where nonspecific lung abscesses are most often seen. Some confirmation that lung abscesses arise in this way comes from the frequent finding that the bacteria causing them are often the same as those associated with dental sepsis, upper respiratory infections, and preceding nasopharyngeal operations in patients who developed such abscesses.

The conjunction of an acute, febrile illness with a profuse mucopurulent sputum and radiological evidence of cavitation is ordinarily sufficient for a diagnosis of lung abscess, the abscess having arisen from suppuration and necrosis of a pneumonic process. Indeed, a lung abscess is inevitably part of a pneumonia, and either may predominate. In the early stages no more than an aspiration pneumonia ${ }^{2}$ is seen. If necrosis is then widespread, a lung abscess is diagnosed; alternatively a "spreading suppurative pneumonia" may develop. ${ }^{3}$ When the aspirated material is liquid or semiliquid, such as vomit, a diffuse bronchopneumonia with a predisposition to abscess formation may occur. H. Nicholson 4 favours the term "nonspecific suppurative pneumonia" for the whole group once necrosis has started.

Several recent American articles have referred to "primary lung abscess," 5-8 but this would seem to be an undesirable choice of words. Admittedly the aspiration of infected material

1 Brock, R. C., The Anatomy of the Bronchial Tree. London, Oxford University Press, 1946.

Scadding, J. G., in Diseases of the Chest, ed. G. Marshall and K. M. A. Perry, p. 123. London, Butterworths, 1952.

3 Sellors, T. H., Blair, L. G., Houghton, L. E., Thompson, V. C., and Pryce, D. M., Thorax, 1946, 1, 146.

Nicholson, H., Lancet, 1950, 2, 549, 605.

5 Weiss, W., and Flippen, H. F., Archives of Internal Medicine, 1967, 120, 8

Duffy, T. J., and Chofnas, I., American fournal of the Medical Sciences, $1962,243,269$.

Fifer, W. R., Husebye, K., Chedister, C., and Miller, M., Archives of Internal Medicine, 1961, 107, 668.

8 Block, A. J., Wagley, P. F., and Fisher, A. M., Fohns Hopkins Medical fournal, 1969, 125, 19. 
cannot always be proved despite the common association with poor oral hygiene, alcoholism, and fits, but at least the abscess is secondary to pneumonia. A. J. Block and colleagues ${ }^{8}$ note the declining frequency of this disease and could find only 79 examples in a recent ten-year review of patients admitted to the Johns Hopkins Hospital. Experience in Britain must be similar owing to the early treatment with antibiotics of patients threatened with pneumonia.

Though surgical treatment was formerly to be preferred, the management of this formidable disorder is now almost entirely by medical means. The choice of antibiotic is influenced to some extent by the nature of the bacterial flora in the sputum. Often no pathogens can be isolated, especially if antibiotics are given before bacteriological tests are done. Among the aerobic organisms that may be found are pneumococci, streptococci, klebsiellae, and miscellaneous Grampositive and Gram-negative bacteria. Anaerobes should always be sought and are usually present when the sputum is foetid. In practice penicillin is the antibiotic of choice, given in a dose of 4-8 million units a day for three to six weeks according to the severity of the infection, with a smaller dose subsequently if healing is delayed. Bronchoscopy is usually desirable, to exclude other disease such as carcinoma. Postural drainage and the inhalation of warm, humidified air are valuable accessory measures. Surgical resection has little or no place during the first few weeks of treatment, unless a suspicion of carcinoma arises. Later it may be necessary for chronic sepsis in a destroyed lung with bronchiectasis, or possibly for recurrent infections of an open cavity which persist despite prolonged medical treatment.

\section{Metabolic Effects of Oral Contraceptives}

At a symposium held last September by the Associations of Clinical Pathologists and of Clinical Biochemists on the biochemical consequences of oral contraceptives disquiet was expressed about the untoward consequences of taking these hormones. It is valuable, therefore, to have the experts' conclusions published for more deliberate consideration in a supplement to the fournal of Clinical Pathology. ${ }^{1}$ It brings into sharp focus one aspect of the control of reproduction, reviewed in a more general way this year in the British Medical Bulletin. ${ }^{2} \mathrm{~s}$

The ten contributions in the supplement cannot range over all the effects of oral contraceptives, but they do explore in some detail the main biochemical consequences. Not surprisingly the vascular effects feature prominently. Much of the definitive work on them has been done in Great Britain by Professor Richard Doll, F.R.S., and his colleagues, one of whom, Dr. M. P. Vessey, gives an account of the epidemiological relationship between oestrogen-progestogen combinations and venous thrombosis, pulmonary embolism, and cerebral thrombosis. These ill effects are the most disturbing feature of the use of oral contraceptives, and Vessey does well to set the risks in context by comparing them with death rates in a similar population from pregnancy, from cancer, and from motor accidents. Dr. Vessey and Professor Doll, together with Drs. A. S. Fairbairn and G. Glober, report in the B.M.Y.

\footnotetext{
1 The Pill: Biochemical Consequences, ed. M. Sandler and B. Billing. Supplement to the fournal of Clinical Pathology. London, British Medical Association, 1970.

- British Medical Bulletin, 1970, 26, No. 1

British Medical fournal, 1970, 1, 449.
}

this week (page 123) on a further aspect of the relation between oral contraceptives and the risk of thromboembolism. They found that the risk of its occurring after surgical operation was raised some three to four times among women taking oral contraceptives before the operation.

L. Poller's contribution to the symposium complements Vessey's by showing what changes are brought about in blood clotting factors by oral contraceptives, and he observes with admirable restraint that they do not appear to be a desirable side-effect. The thrombotic hazards of the pill are further explored in another article on the effect of oestrogens on platelet action, and members of the Medical Research Council's unit in Glasgow discuss the increase in blood pressure in some women that may result from the effects of oral contraceptives on plasma renin and renin substrate.

It is possible that many of the metabolic effects of oral contraceptives-for example, their effect on carbohydrate metabolism-follow upon their effect on cortisol metabolism. C. W. Burke records the evidence that oestrogen-containing oral contraceptives increase the blood concentration of both free and bound cortisol. He is critical of the idea that this finding implies an increased overall exposure of the tissues to cortisol, and he points out that free cortisol excretion in the urine over 24 hours is only trivially increased by treatment with oral contraceptives. Nevertheless, V. Wynn and J. W. H. Doar in their contribution attribute the impaired glucose tolerance of women on the pill to the raised plasma cortisol, and it is possible that other effects on liver function recorded elsewhere in the supplement are related to altered corticosteroid metabolism.

In this publication the oestrogens are blamed time and again for unwanted side-effects. Thus oral contraceptives consisting of progestogens only should not be hastily condemned. But at best they are a stopgap measure, much less effective as contraceptives than the oestrogen-progestogen mixtures. The searching examination which the symposium devotes to the side-effects of oral contraceptives does not make a case for discontinuing them, but it does imply that the present ones should be replaced as soon as equally simple and effective means can be devised which are less of an endocrinological insult.

\section{Neonatal Necrotizing Enterocolitis}

Necrotizing enterocolitis is a well-recognized but incompletely understood disorder of early infancy, affecting particularly premature infants and those who have had exchange transfusions. $^{1-7}$ It usually begins in the first week of life, though cases have occurred in later infancy. ${ }^{6}$

The infant will commonly have suffered from birth asphyxia, hyaline membrane disease, apnoeic attacks, or jaundice. Feeds begin to pool in the stomach, and the baby may vomit; the vomit or gastric aspirate become bile-stained. The abdomen distends and bowel sounds may disappear. (These early signs are those of intestinal obstruction, which has many possible causes in the neonatal period. ${ }^{8}$ ) The baby sometimes passes no stools but, more frequently, small amounts of blood-stained stool. Frank diarrhoea is rare. In severe cases perforation of the ileum or colon may occur, leading to peritonitis, shock, generalized sepsis, and death. The mucous membrane of the gut, especially in the terminal ileum and ascending colon, undergoes haemorrhagic necrosis. ${ }^{12}{ }^{6} 7$ Areas of mucosa may slough off, and in other areas there are submucosal gas-filled cysts. 